OPEN ACCESS

Edited by:

Stefan Geisen,

Netherlands Institute of

Ecology (NIOO-KNAW), Netherlands

Reviewed by:

Roey Angel,

Biology Centre (ASCR), Czechia

Osnat Gillor,

Ben-Gurion University of the Negev,

Israel

*Correspondence:

Don A. Cowan

don.cowan@up.ac.za

Specialty section:

This article was submitted to

Terrestrial Microbiology,

a section of the journal

Frontiers in Microbiology

Received: 02 November 2018 Accepted: 26 April 2019

Published: 14 May 2019

Citation:

León-Sobrino C, Ramond J-B, Maggs-Kölling $G$ and Cowan DA (2019) Nutrient Acquisition, Rather

Than Stress Response Over Diel Cycles, Drives Microbial Transcription in a Hyper-Arid Namib Desert Soil.

Front. Microbiol. 10:1054.

doi: 10.3389/fmicb.2019.01054

\section{Nutrient Acquisition, Rather Than Stress Response Over Diel Cycles, Drives Microbial Transcription in a Hyper-Arid Namib Desert Soil}

\author{
Carlos León-Sobrino ${ }^{1}$, Jean-Baptiste Ramond ${ }^{1}$, Gillian Maggs-Kölling ${ }^{2}$ and \\ Don A. Cowan ${ }^{1 *}$ \\ ${ }^{1}$ Centre for Microbial Ecology and Genomics, University of Pretoria, Pretoria, South Africa, ${ }^{2}$ Gobabeb Research and Training \\ Centre, Gobabeb, Namibia
}

Hot desert surface soils are characterized by extremely low water activities for large parts of any annual cycle. It is widely assumed that microbial processes in such soils are very limited. Here we present the first metatranscriptomic survey of microbial community function in a low water activity hyperarid desert soil. Sequencing of total mRNA revealed a diverse and active community, dominated by Actinobacteria. Metatranscriptomic analysis of samples taken at different times over 3 days indicated that functional diel variations were limited at the whole community level, and mostly affected the eukaryotic subpopulation which was induced during the cooler night hours. High levels of transcription of chemoautotrophic carbon fixation genes contrasted with limited expression of photosynthetic genes, indicating that chemoautotrophy is an important alternative to photosynthesis for carbon cycling in desiccated desert soils. Analysis of the transcriptional levels of key $\mathrm{N}$-cycling genes provided strong evidence that soil nitrate was the dominant nitrogen input source. Transcriptional network analyses and taxon-resolved functional profiling suggested that nutrient acquisition processes, and not diurnal environmental variation, were the main drivers of community activity in hyperarid Namib Desert soil. While we also observed significant levels of expression of common stress response genes, these genes were not dominant hubs in the co-occurrence network.

Keywords: desert actinobacteria, metatranscriptome analysis, chemoautotrophic $\mathrm{CO}_{2}$ fixation, diel activity cycles, stress resistance and tolerance, deserts and dryland ecosystems, soil microbial activity, RNA-seq

\section{INTRODUCTION}

Arid lands (deserts) are defined as having a level of precipitation $(\mathrm{P})$ below the potential evapotranspiration $(\mathrm{PET})$ level $(\mathrm{P} / \mathrm{PET}<1)$. Such lands cover an estimated one-third of Earth's terrestrial surface (Laity, 2008) and are projected to expand in current climate change scenarios (Reich et al., 2001). The Namib Desert, located along the western coast of Namibia and extending into southern Angola and northern South Africa, is the oldest (ca. 5 million years) continuously hyperarid (P/PET < 0.05) desert on Earth (Seely and Pallet, 2008). 
According to current models, aridity results in habitat fragmentation, both geographically, leading to "islands" of microbial biomass and diversity and, temporally, producing long periods of functional inactivity (Pointing and Belnap, 2012; Collins et al., 2014). Recent evidence from ATP measurements and rRNA transcript analyses suggest that some microorganisms remain active under these extreme conditions, although the active functions have not yet been detailed (Gunnigle et al., 2017; Schulze-Makuch et al., 2018).

In recent years, the microbial ecology of various Namib Desert edaphic niches has been extensively studied, highlighting the importance of water availability and soil chemistry (particularly phosphorus and ammonia) in microbial community assembly and function (Frossard et al., 2015; Ronca et al., 2015; Johnson et al., 2017; Scola et al., 2017).

RNA sequencing has been employed to study microbial community functional patterns in many different aquatic and terrestrial ecosystems. The short life-span and high turnover of messenger RNA (Belasco and Brawerman, 1993) allows ephemeral states of microbial communities to be captured without significant interference from legacy biomolecules or inactive microbial populations, as might be the case in $16 \mathrm{~S}$ rRNA transcript-, DNA- or protein-based studies (Nielsen et al., 2006; Blazewicz et al., 2013). mRNA provides a better insight into the growth stage of prokaryotic communities than 16S RNA gene transcripts, as the later can also originate from dormant and/or recently deceased cells (Blazewicz et al., 2013). In desert environments, active prokaryotic communities have been identified by targeted 16S rRNA amplicon transcriptomics studies, demonstrating a diel pattern for several actinobacterial and proteobacterial taxa during dry periods (Gunnigle et al., 2017), and a dramatic activation of gamma-Proteobacteria, Firmicutes, and Bacteroidetes after rainfall (Štovíček et al., 2017).

In this study, we analyzed 12 shotgun metatranscriptomes from hyperarid desert soils sampled over 3 days. The experiment was designed to assess the diel transcriptional activity of desert edaphic microbial communities, particularly focusing on nutrient acquisition and stress response mechanisms. We also aimed to identify the key community members responsible for nutrient (C, N, P) cycling. Given the variations in light, temperature and humidity to which desert soil communities are exposed within a daily cycle, we hypothesized that functional transcriptional profiles would also show distinct diurnal cycles.

\section{MATERIALS AND METHODS}

\section{Sampling Procedure}

The sampling site was located in the calcrete gravel plains of the central Namib Desert $\left(23^{\circ} 33^{\prime \prime} 34^{\prime \prime} \mathrm{S} 15^{\circ} 02^{\prime} 25^{\prime \prime} \mathrm{E}\right)$ (Scholz, 1972), Namibia, approximately $56 \mathrm{~km}$ from the coast. The mean annual precipitation at the site is estimated at $25 \mathrm{~mm}$, principally derived from nocturnal marine fog (Eckardt et al., 2013). We implemented a 3 day sampling strategy with soil collection at near sunrise $(6: 00 \mathrm{~h})$, at midday $(12: 00 \mathrm{~h})$, at near sunset $(18: 00 \mathrm{~h})$, and at midnight $(24: 00 \mathrm{~h})$. A $10 \times 10 \mathrm{~m}$ experimental plot was subdivided into 64 quadrats (Supplementary Figure S1). Surface soils $(0-4 \mathrm{~cm})$ were collected at six hourly intervals at near sunrise, midday, near sunset and midnight (6:00, 12:00, 18:00, and 24:00 h) over 3 days from the 12th to the 14th April 2016, after a prolonged dry period (> 1 year, Supplementary Table S1). Two Hygrochron iButton sensors (Embedded Data Systems, Lawrenceburg, KY, United States) were positioned at the corners of the plot, at $\sim 2 \mathrm{~cm}$ depth, recording temperature and relative humidity at $4 \mathrm{~min}$ intervals for the length of the experiment (Supplementary Figure S1). Soil respiration measurements were performed at the designated sampling times at four points within the plot using a LI-8100 IRGA (LI-COR Biosciences, Lincoln, NE, United States), covering an area of $83.7 \mathrm{~cm}^{2}$ with a $3 \mathrm{~L}$ chamber for $30 \mathrm{~s}$ (Supplementary Figure S1). Photosynthetically active radiation (PAR) was measured using a photometric sensor (Quantum, LI-COR) at the same internal plot locations. Surface soil samples $(0-4 \mathrm{~cm})$ were collected at six hourly intervals $(6: 00,12: 00,18: 00$, and 24:00 h) over 3 days from the 12 th to the 14th April 2016. Three randomly selected quadrats were sampled at each time point (Supplementary Figure S1). $20 \mathrm{~g}$ soil samples were immediately preserved on-site in RNAlater solution (Sigma-Aldrich, St. Louis, MO, United States), temporarily stored at $-20^{\circ} \mathrm{C}$ at the Gobabeb Research and Training Centre and during transport to the laboratory, and subsequently at $-80^{\circ} \mathrm{C}$ prior to total RNA extraction. An additional $400 \mathrm{~g}$ of soil for physicochemical analysis was collected in WhirlPak bags (Nasco, Fort Atkinson, WI, United States), preserved at $4^{\circ} \mathrm{C}$ and homogenized by sieving through a $2 \mathrm{~mm}$ mesh before physicochemical analyses. Soil $\mathrm{pH}$, conductivity, cation exchange capacity (CEC), total nitrogen $(\% \mathrm{~N})$, phosphorus $(\mathrm{P})$, sodium $(\mathrm{Na})$, potassium $(\mathrm{K})$, calcium $(\mathrm{Ca})$, magnesium $(\mathrm{Mg})$, Chloride $(\mathrm{Cl})$, Sulfate $\left(\mathrm{SO}_{4}\right)$, ammonium $\left(\mathrm{NH}_{4}\right)$, and nitrate $\left(\mathrm{NO}_{3}\right)$ contents were analyzed by Bemlab (Pty) Ltd. ${ }^{1}$, (Strand, Western Cape, South Africa) using standard protocols.

\section{Total RNA Purification}

Soils from 12 physicochemically similar quadrats representing all sampling times were selected for RNA extraction (Supplementary Figure S1 and Supplementary Table S2). $20 \mathrm{~g}$ of frozen, RNAlater-preserved soils were thawed at $4^{\circ} \mathrm{C}$, centrifuged at $14,500 \mathrm{rpm}$ for $5 \mathrm{~min}$ and supernatants were discarded. 5 volumes of ice-cold $10 \mathrm{mM}$ Tris-HCl $1 \mathrm{mM}$ EDTA pH 6.5 buffer containing $100 \mathrm{mM} \mathrm{NaH}_{2} \mathrm{PO}_{4}$ were added to the soil to remove RNAlater salts. The supernatant was discarded after rapid $(4 \mathrm{~min})$ centrifugation at $4^{\circ} \mathrm{C}$. 0.5 volumes lysis buffer (5\% CTAB, $0.7 \mathrm{M} \mathrm{NaCl}, 240 \mathrm{mM} \mathrm{KH}_{2} \mathrm{PO}_{4}, \mathrm{pH}$ 8) and an equal volume of TRI Reagent (Sigma-Aldrich) were added, and samples were vortexed at high speed for $30 \mathrm{~s}$. RNA purification proceeded according to the manufacturer's instructions. Extracted and purified total RNA was incubated with DNAseI (Invitrogen, Carlsbad, United States) for $15 \mathrm{~min}$ following the manufacturer's instructions and precipitated in the presence of $20 \%$ isopropanol and $15 \mathrm{ng}$ glycogen co-precipitant (GlycoBlue, Invitrogen). RNA purity and concentration were analyzed using

\footnotetext{
${ }^{1}$ http://www.bemlab.co.za/
} 
a NanoDrop 2000 spectrophotometer (Thermo Fisher Scientific, Waltham, United States). RNA integrity and the absence of DNA contamination were confirmed in $1 \%$ agarose gel electrophoresis. The absence of RT-PCR inhibitors was tested using the Transcriptor cDNA Synthesis Kit v9 (Roche, Indianapolis, IN, United States) and universal bacterial 16S rRNA gene primers E9F (5'-GAGTTTGATCCTGGCTCAG-3') and U1510R (5' GGTTACCTTGTTACGACTT-3') (Reysenbach and Pace, 1995; Hansen et al., 1998).

\section{Library Construction and Sequencing}

One microgram DNA-free total RNA from each sample was used for each sequencing library. Due to low RNA yields, we combined RNA from two Day 2 6:00 h quadrats (Supplementary Table S1). Construction of rRNA-depleted libraries was carried out with the ScriptSeq Complete Gold Kit (Epidemiology) (Epicentre, Madison, WI, United States), following the manufacturer's instructions. Briefly, rRNA was removed by hybridization with bead-immobilized prokaryotic and eukaryotic 28S, 23S, $18 \mathrm{~S}, 16 \mathrm{~S}, 5.8 \mathrm{~S}, 5 \mathrm{~S}, \mathrm{mt} 16 \mathrm{~S}$, and mt12S probes prior to RNA fragmentation and reverse transcription with tagged random hexamer primers. cDNA was amplified with TruSeq adaptors containing unique indexes (ScriptSeq Primer Set 1, Epicentre) for 15 PCR cycles. Libraries were purified using AMPure XP beads (Beckman-Coulter, Brea, United States) and final yields were measured with the High Sensitivity dsDNA reagents on a Qubit 2.0 fluorometer (Invitrogen). Multiplexed samples were quality and size analyzed in a High Sensitivity D1000 TapeStation (Agilent, Waldbronn, Germany). Libraries were single-end sequenced in a NextSeq500 v2 platform using the NextSeq 500/550 High Output v2 kit (Illumina, San Diego, United States). RNA-seq data were deposited in the ArrayExpress database ${ }^{2}$ and can be accessed using the reference E-MTAB-6601.

Read quality trimming was performed using Prinseq-lite v0.20.4 (Schmieder and Edwards, 2011) on both read ends with a mean Phred value of $\geq 30$ in a 6 base sliding window. Reads shorter than 40 bases after trimming were discarded. rRNA and human-derived reads were removed from the dataset using Bowtie2 (Langmead and Salzberg, 2012) with a database of large- and small ribosomal subunit genes from SILVA ${ }^{3}$, 5S rRNA genes from the 5SRNAdb repository (Szymanski et al., 2016) and the GRCh38 human genome primary assembly ${ }^{4}$.

\section{Analysis of Sequencing Reads}

Functional and taxonomic profiling, and differential transcription analyses were performed using $\mathrm{R}$ version 3.3.3 (R Core Team, 2017). Read taxonomy was inferred from the NCBI Reference Sequence (RefSeq) database, and function was assigned based on the Kyoto Encyclopedia

\footnotetext{
${ }^{2}$ www.ebi.ac.uk/arrayexpress

${ }^{3}$ https://www.arb-silva.de/

${ }^{4} \mathrm{ftp}$ ://ftp.ncbi.nlm.nih.gov/genomes/archive/old_genbank/Eukaryotes/ vertebrates_mammals/Homo_sapiens/GRCh38/seqs_for_alignment_pipelines/ GCA_000001405.15_GRCh38_no_alt_analysis_set.fna.bowtie_index.tar.gz
}

of Genes and Genomes (KEGG) Orthologs (KO) database (Kanehisa et al., 2016) using the MG-RAST server ${ }^{5}$ (Meyer et al., 2008). Read count tables were assembled and analyzed for temporal transcriptional changes using the ANOSIM permutation test with 999 permutations (Oksanen et al., 2017) and the EdgeR package (Robinson et al., 2010) for all genes with $>1$ count per million (cpm) in at least 3 libraries $(n=11)$. Normalized KEGG ortholog counts were fitted to a generalized log-linear model ( $g \operatorname{lm} Q L F i t$ function) (Robinson and Oshlack, 2010; McCarthy et al., 2012; Lun et al., 2016), and pairwise comparisons between all time points were performed. Additionally, grouped "day" samples from 12:00 and 18:00 h were compared to "night" samples from 24:00 and 6:00 h. KOs were considered significantly differentially expressed between time points below a false discovery rate (FDR) corrected $p$-value threshold of 0.05 .

Orthologs with average $\log _{2} \mathrm{CPM}$ values $>7$ were used to construct a transcriptional network (Figure 4), excluding KEGG categories Human Diseases and Organismal Systems. This threshold was selected as being below the common dispersion value calculated during differential expression analysis in order to reduce interference from high-variance, low-abundance transcripts. A transcriptional network was constructed using MENA's (Deng et al., 2012) RMT-based modeling with a correlation cutoff of $0.900(p \leq 0.005)$. Co-transcription was determined using Pearson's correlation coefficients across libraries $(n=11)$. The network was visualized using Cytoscape v. 3.5.1 (Shannon et al., 2003).

\section{RESULTS AND DISCUSSION}

\section{Soil Physicochemical Characteristics}

Surface soil temperatures ranged from 21.4 to $51.3^{\circ} \mathrm{C}$, and soil atmospheric humidity ranged from 13 to $27.7 \%$ (Supplementary Figure S2). An average PAR flux of $1722 \pm 22 \mu \mathrm{mol}$ photons $\mathrm{m}^{-2} \mathrm{~s}^{-1}$ was measured at 12:00 h, but was negligible or zero at 6:00, 18:00, and 24:00 h. Consistent soil respiration was recorded throughout the experiment (Supplementary Table S2).

The physicochemistry of soil samples was globally homogeneous. Localized heterogeneity was observed in four quadrats and related mostly to salt or phosphate concentration (Supplementary Table S2 and Supplementary Figure S3).

\section{Library Construction and Sequence Data}

A sample from each time point was selected for library construction $(n=12)$ based on homogenous soil physicochemical characteristics. Sequencing of cDNA libraries produced 285 million reads in total, with an average read length of $76 \mathrm{nt}$. After quality filtering and discarding rRNA and humanderived reads, 268 million high-quality reads were retained (Supplementary Table S3). Due to the instability of mRNA under typical desert soil conditions (as a result of oxidative damage, and radiation and desiccation-induced fragmentation (Rajeev et al., 2013), we consider that transcripts analyses provide

\footnotetext{
${ }^{5}$ http://metagenomics.anl.gov/
} 
a valid indication of recent transcriptional activity within the soil microbial population.

\section{Taxonomic Composition of the Active Soil Microbial Community}

The taxonomic composition of the active microbial populations deduced from non-rRNA read sequences was similar throughout the study period (Supplementary Figure S4), in spite of observed variations in temperature, humidity and light (Supplementary Figure S2 and Supplementary Table S2). A single exception was the Day 2, 24:00 h library, which contained an unusually large proportion of fungal (19.5\%, compared to an average of $2.8 \%$ in the remaining libraries) and Firmicutes (38.5\%, compared to $5.9 \%$ ) phylotypic sequences (Supplementary Figure S4). This result most likely represented random localized soil variation and not an effect of the sampling time. Fungal transcripts suggest that this could be an organic matter decomposition hotspot (Jacobson et al., 2015). This library was excluded from further analyses, as we aimed to describe diel activity in the "homogeneous" soil microbial community.
The phylogenetic analysis of the remaining 11 libraries showed that members of the domain Bacteria were most active (94.2 $\pm 2.6 \%$ of transcripts), with Eukarya comprising $4.3 \pm 1.8 \%$ and Archaea $1.5 \pm 1.0 \%$. Virus-classified reads amounted to $0.04 \pm 0.02 \%$ (Figure 1A). Despite representing only a minor proportion, this is, to our knowledge, the first report of transcriptionally active viruses in dessicated hot desert soils, where lysogeny is considered to be the dominant state of virus populations (Zablocki et al., 2015). However, the read volume was insufficient to provide a comprehensive survey of transcribed viral genes.

Seven bacterial phyla (Actinobacteria, Proteobacteria, Firmicutes, Bacteroidetes, Chloroflexi, Cyanobacteria, and Deinococcus-Thermus) and one eukaryal phylum (Ascomycota) each contributed more than $1 \%$ of the classified reads, jointly comprising $93.1 \pm 2.3 \%$ of the total active community (Figure 1A and Supplementary Figure S4). The most active phylum globally was Actinobacteria, producing $52.1 \pm 5.4 \%$ of the classified transcripts, followed by Proteobacteria, with $20.2 \pm 2.6 \%$ of the transcripts. Two prominent actinobacterial families, Geodermatophilaceae and Rubrobacteraceae, represented $8.2 \pm 1.8 \%$ and $7.0 \pm 1.9 \%$, respectively (Figure 1A). Both

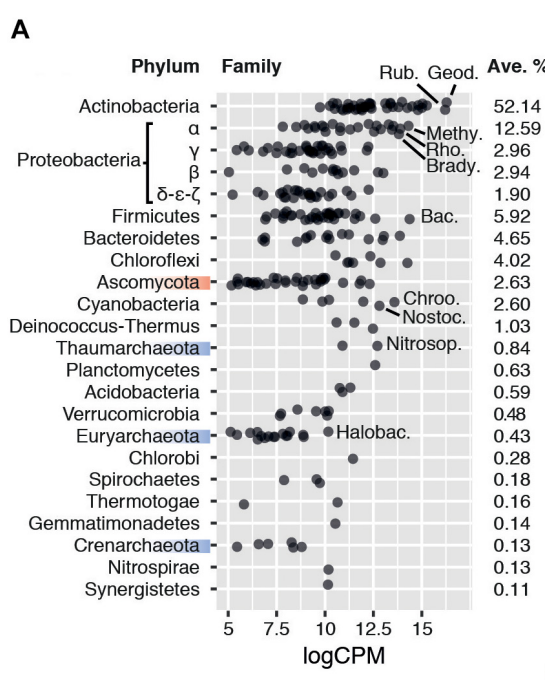

B

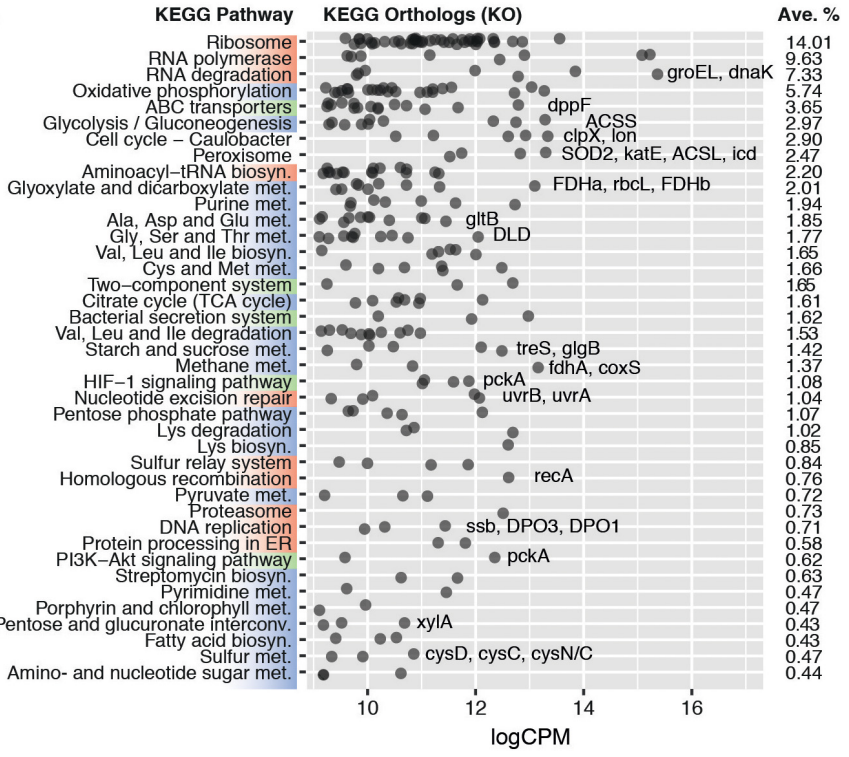

FIGURE 1 | (A) Average transcriptional activity of the 20 most transcriptionally active microbial phyla and families. Phyla are sorted according to their average transcription levels (aveLogCPM function). Family transcript abundance is given in average $\log _{2}$ counts per million (logCPM). Geod.: Geodermatophilaceae; Rub.: Rubrobacteriaceae; Methy.: Methylobacteriaceae; Rho.: Rhodobacteraceae; Brady.: Bradyrhizobiaceae; Bac.: Bacillaceae; Chroo.: Chroococcales; Nostoc.: Nostocaceae; Nitrosop.: Nitrosopumilaceae; Halobac.: Halobacteriaceae. (B) Average transcript abundance of KEGG orthologs in the 40 most transcriptionally active KEGG pathways. Pathways are sorted according to their average $\log _{2}$ counts per million (aveLogCPM function). Upper KEGG classes are highlighted on the left axis by color: Genetic Information Processing (red), Metabolism (blue), and Environmental Information Processing (green). Categories Human Diseases and Organismal Systems were not included in the plot. Orthologs of particular interest are named, in order of transcript abundance, besides their respective pathway. ACSL, acyl-CoA synthetase; ACSS, acetyl-CoA synthetase; clpX, Clp protease ATP-binding subunit; coxS, carbon-monoxide dehydrogenase small subunit; cysD, sulfate adenylyltransferase subunit 2; cysC, adenylylsulfate kinase; cys N/C, bifunctional enzyme CysN/CysC; DLD, dihydrolipoamide dehydrogenase; $d$ naK, molecular chaperone DnaK; DPO1/3, DNA polymerase I/III; dppF, dipeptide transport system ATP-binding protein; FDHa/b, formate dehydrogenase alpha/beta subunit; fdhA, formaldehyde dehydrogenase; glgB, 1,4-alpha-glucan branching enzyme; gltB, glutamate synthase; groEL, chaperonin GroEL; icd, isocitrate dehydrogenase; katE, catalase; Ion, Lon protease; pckA, phosphoenolpyruvate carboxykinase; rbcL, ribulose-bisphosphate carboxylase large chain; recA, recombination protein RecA; SOD2, superoxide dismutase; ssb, single-strand DNA-binding protein; treS, maltose alpha-D-glucosyltransferase/alpha-amylase; $u v r A / B$, excinuclease $A B C ; x y / A$, xylose isomerase. 
families have been routinely detected in desert soils and their members typically exhibit high stress tolerance and are metabolically versatile (Rainey et al., 2005; Favet et al., 2013; Albuquerque and da Costa, 2014; Normand et al., 2015; Sghaier et al., 2016).

\section{Functional Profile of the Microbial Community}

All core metabolic pathways were transcribed (Figure 1B), including replication genes, indicating that the active fraction of the soil microbial community had complete functionality. This transcriptional profile strongly suggests that the sequenced mRNA did not originate from spores or other dormant forms, which have been shown to only accumulate selected transcripts related to resuscitation processes for a period after the onset of dormancy (Segev et al., 2012; Rajeev et al., 2013).

The transcriptional profiles strongly suggest the existence of a xero resistant microbial community in this hyperarid desert soil niche. Tolerance; i.e., survival with impaired or no activity and no growth, is regarded as the most common strategy adopted by microbial communities under extreme xeric stress, such as in hyperarid desert soils (Lebre et al., 2017). Active microbial populations have recently been detected in hyperarid soils: from the Atacama Desert by measuring ATP (Schulze-Makuch et al., 2018) and in Namib Desert gravel plain soils from the determination of respiration rates (Armstrong et al., 2016). Our transcription results, which demonstrate that at least a fraction of the microbial community is functional, suggest that resistance, rather than tolerance, is a strategy adopted by some of the resident taxa. Resistance is here defined as the maintenance of function, despite the impositions of extreme environmental parameters (i.e., hyperaridity) (Harrison et al., 2007).

Genes encoding elements of stress resistance and damage repair mechanisms were highly transcribed. Chaperone genes groEL and $d n a K$ (4.9\% and $1.5 \%$ of the classified transcripts, respectively) (Figure 1B), and protease genes involved in protein quality control (e.g., $c l p X / P$ and $l o n ; 1.7 \%$ and $0.7 \%$, respectively) were among the most transcribed. Furthermore, the high relative abundances of peroxisomal orthologs $(2.4 \%)$, such as superoxide dismutase (SOD) and catalase (katE), as well as DNA repair gene transcripts ( $r e c A, u v r$, Figure 1B), support the widely held view that radiation- and desiccation-induced damage (particularly related to oxidation processes) are the major stresses for microbial cells in hyperarid hot desert soils (Makhalanyane et al., 2015). The production of compatible solutes and capsule formation, which are common microbial adaptation mechanisms for desiccation tolerance (Lebre et al., 2017), were suggested by polysaccharide and trehalose biosynthesis gene transcripts such as the alpha-glucan branching enzyme gene $\operatorname{glg} B(0.4 \%$ of transcripts) (Rashid et al., 2016; Figure 1B). Overall, the transcriptional profile of the microbial community coherently reflects known strategies of desiccation resistance predicted from genomic analyses of desiccation-tolerant microorganisms (Lebre et al., 2017; Schulze-Makuch et al., 2018). Furthermore, given the transcription of most core metabolic pathways (particularly, of growth-related gene transcripts), we conclude that a fully active population remains during periods of hyperaridity.

\section{Nutrient Cycling and Key Active Taxa}

Carbon, nitrogen, and phosphorus are the major limiting nutrients for soil microbial communities, and for oligotrophic desert soil communities in particular (Cleveland and Liptzin, 2007; Delgado-Baquerizo et al., 2013; Johnson et al., 2017). The transcriptional activity of orthologs involved in nitrogen species reduction to assimilable ammonia, phosphorus import in organic or inorganic forms, sulfur reduction, and inorganic carbon fixation in the community was examined in further detail.

High levels of functional redundancy were evident (Figure 2). However, some important ecosystem functions appeared to be taxon-specific. For example, nitrate reductase (nar) genes, which encode key enzymes in nitrogen assimilation in soils (Merrick and Edwards, 1995; Figure 3A), were transcribed almost exclusively by members of the Nitrospiraceae family (Figure 2A), indicating that this family plays a key role in the nitrogen cycling of Namib desert soil communities.

\section{Nitrogen Assimilation}

Nitrogen-fixing bacterial taxa such as Geodermatophilaceae, Frankiaceae and Rhizobiales (Merrick and Edwards, 1995; Sellstedt and Richau, 2013) were among the most active taxa (Figure 1A). However, transcripts relating to the nitrogen metabolism KEGG pathway represented a small portion $(0.2 \%)$ of our soil metatranscriptomes and virtually no nifD nitrogenase transcripts were detected (Figure 3A). These findings are compatible with recent observations that hypolithic communities, and not surface soil communities, were the primary sources of $\mathrm{N}_{2}$-fixation in Namib Desert gravel plains (Ramond et al., 2018).

Transcriptome data suggested that nitrate reduction, most transcribed by the Nitrospiraceae family, and nitrite reduction, primarily transcribed in actinobacterial taxa (nar and nir genes, respectively, Figure $\mathbf{2 A}$ ), were the dominant processes in the generation of biologically available nitrogen in the community from a $\mathrm{NO}_{3}{ }^{-}$and $\mathrm{NO}_{2}^{-}$reservoir (Figure 3A). These nitrogen species may be accumulated in soils during infrequent wet periods, possibly as a result of the activation of genes and microorganisms inhibited during desiccated conditions (Scherer et al., 1984), or from atmospheric deposition processes (Báez et al., 2007; Jia et al., 2016).

\section{Phosphorus and Sulfur Assimilation}

Most phosphorus is available to soil microbial communities as inorganic phosphate $(\mathrm{Pi})$, solubilized from the mineral soil fraction or released from organic molecules by the alkaline phosphatase (White and Metcalf, 2007). Pst phosphate transporter gene transcripts were abundant in the community (1390 average counts per million, cpm). Organic phosphate sources were also possibly exploited, as suggested by transcription of the phn phosphonate transporter gene $(153 \mathrm{cpm})$ and especially the sn-glycerol 3-phosphate (G3P) transporter gene ugp $(1228 \mathrm{cpm})$ (Figure 3B). Although the expression of phn and $u g p$ can be inhibited by Pi (Schowanek and Verstraete, 1990; 
A

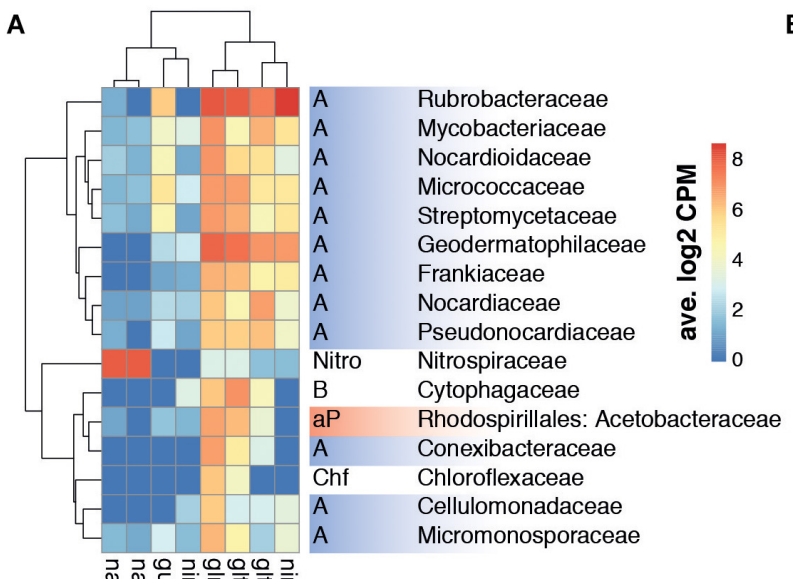

C

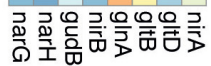

B

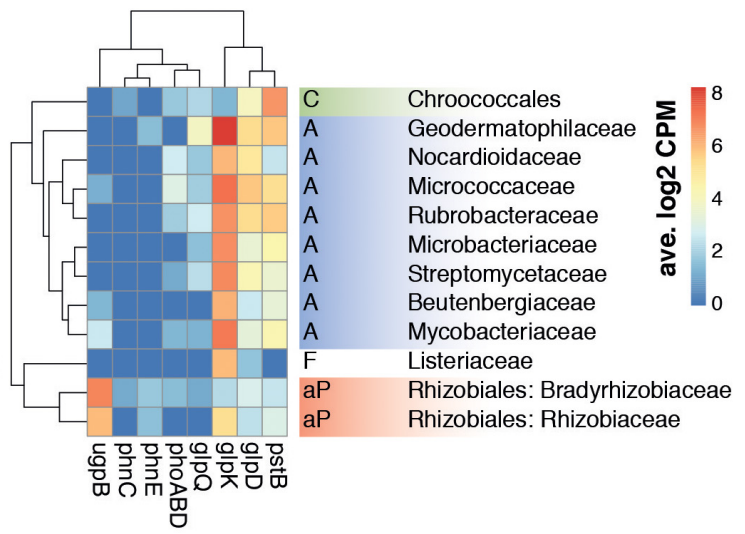

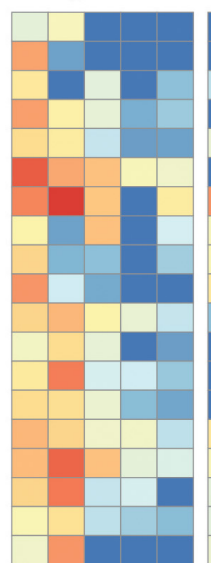
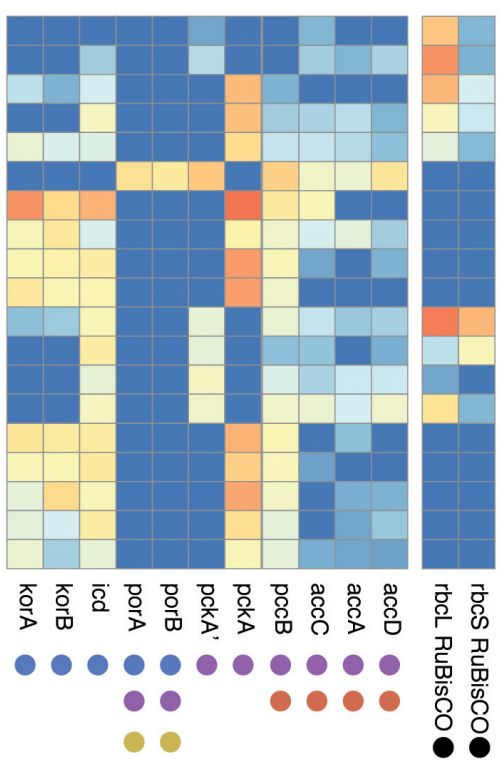

gP Chromatiaceae

\begin{tabular}{|c|c|c|}
\hline$g P$ & Chromatiaceae & \\
\hline $\mathrm{C}$ & Chroococcales & \\
\hline A & Thermomonosporaceae & \\
\hline $\mathrm{bP}$ & Burkholderiales: Burkholderiaceae & \\
\hline bP & Burkholderiales: Comamonadaceae & \\
\hline A & Rubrobacteraceae & \\
\hline A & Geodermatophilaceae & \\
\hline Chf & Chloroflexaceae & \\
\hline
\end{tabular}

A Frankiaceae

A Streptomycetaceae

aP Rhizobiales: Bradyrhizobiaceae

aP Rhizobiales: Rhizobiaceae

aP Rhizobiales: Methylobacteriaceae

aP Rhodobacterales: Rhodobacteraceae

A Nocardioidaceae

A $\quad$ Pseudonocardiaceae

A Mycobacteriaceae

A Nocardiaceae

dP Myxococcaceae

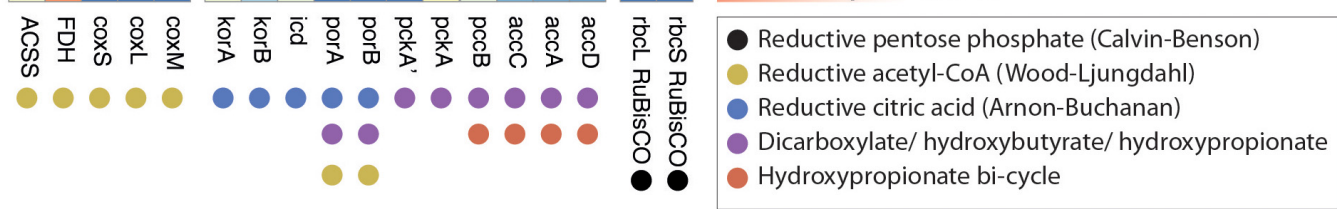

FIGURE 2 | Correlation between family level taxonomy and key KEGG ortholog transcription from nitrogen (A), phosphorus (B), and carbon (C) assimilation pathways in selected prokaryotic taxa. (A) Nitrogen metabolism orthologs: gln, glutamine synthetase; glt, glutamate synthase; gud, glutamate dehydrogenase; nar, nitrate reductase; nir, nitrite reductase. (B) Phosphorus assimilation and G3P metabolism orthologs: glpD, glycerol 3-phosphate dehydrogenase; g/pK, glycerol kinase; glpQ, glycerophosphodiester phosphodiesterase; phn, phosphonate transport; phoABD, alkaline phosphatase; pst, phosphate transport; ugp,

sn-glycerol-3-phosphate transport. (C) Carboxylase gene orthologs involved in carbon fixation pathways: ACSS, acetyl-CoA synthase; acc, acetyl-CoA carboxylase; $\mathrm{FDH}$, formate dehydrogenase; icd, isocitrate dehydrogenase; kor, 2-oxoglutarate synthase; cox, CO dehydrogenase; pcc, acetyl/propionyl-CoA carboxylase; pck, PEP carboxylase; por, pyruvate synthase; rbc, RuBisCO. Phylum abbreviations: A: Actinobacteria; B: Bacteroidetes; C: Cyanobacteria; Chf: Chloroflexi; F: Firmicutes; Nitro: Nitrospirae; P: Proteobacteria (a: alpha, b: beta, d: delta, g: gamma). Only families with $>6$ average $\log _{2} \mathrm{CPM}$ for the selected genes were included in $\mathbf{A}$ and $\mathbf{B}$. Hierarchical clustering of rows and columns was performed with hclust function.

Brzoska et al., 1994), organic P utilization may still be an important microbial community trait in oligotrophic desert environments (Vikram et al., 2016). The ugp genes were principally transcribed by members of the Order Rhizobiales (Class alpha-Proteobacteria), potentially replacing Pi transport as a phosphorus acquisition mechanism (Figure 2B). Plant exudates or membrane phospholipids are possible sources of G3P in soils (Ding et al., 2012; Collins et al., 2014; Lidbury et al., 2017). The $g l p Q$ gene product can cleave these compounds, releasing G3P and triggering activation of the ugp transporter genes (Brzoska and Boos, 1988). GlpQ is an extracellular enzyme which has been implicated in cooperative interactions between proteobacteria (Lidbury et al., 2017). In our dataset, $g l p Q$ was mostly transcribed in Actinobacteria. The most active actinobacterial family Geodermatophilaceae, however, transcribed $g l p Q$, but not the G3P transporter $g l p$ or the alkaline phosphatase pho genes, which would dephosphorylate G3P, releasing Pi for its own consumption (Figure 2B). Our data therefore suggest a putative interaction between Geodermatophilaceae and Rhizobiales, with the former providing access to phosphorus as G3P for the latter. This interaction may be of considerable importance for desert community maintenance, as both taxa 
A

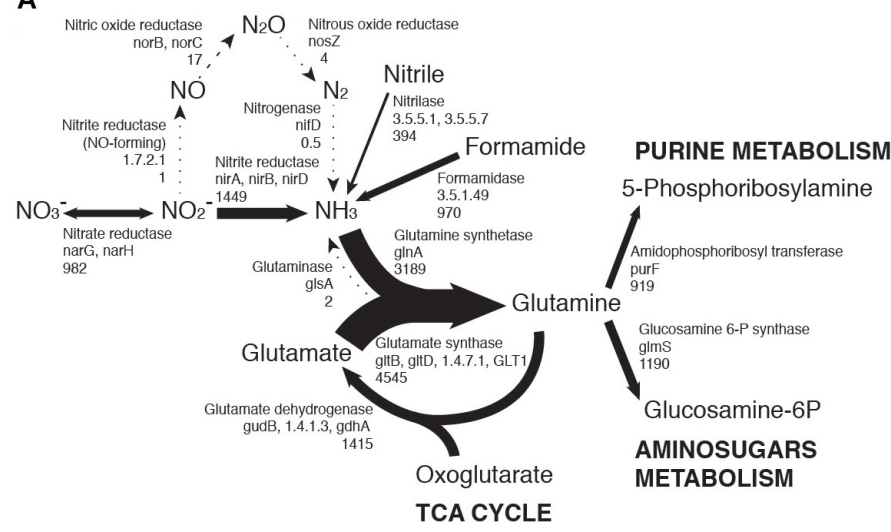

B

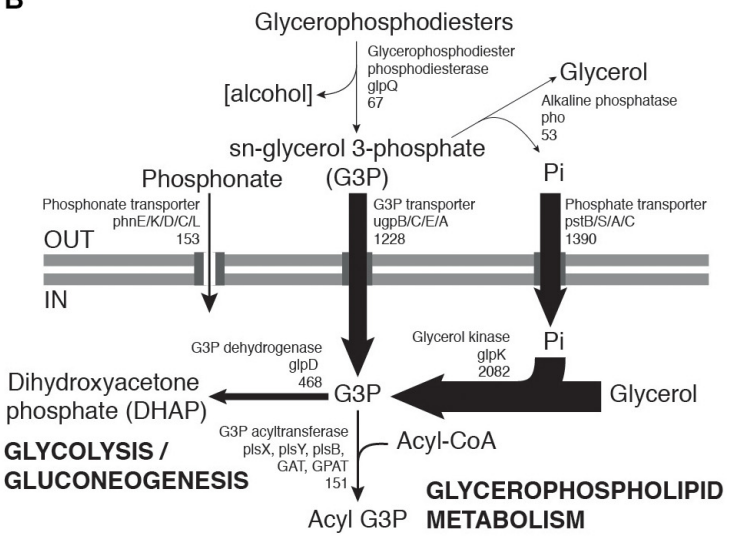

FIGURE 3 | Community-level transcription of nitrogen (A) and phosphorus (B) assimilation pathways, including glycerol phosphate metabolism. Gene codes in bold highlight the most abundant orthologs from a group performing the same function, when there is a large transcript abundance difference. Numbers below gene codes show the total average counts per million (cpm) of all orthologs. Arrow thickness in each figure is proportional to the indicated cpm value.

were amongst the most transcriptionally active $(8.2 \%$ and $6.1 \%$, respectively) (Figure 1A).

Reductive sulfate assimilation (cys genes) was the dominant transcribed S-cycling pathway in the community. However, transcripts for the sulfate transporter cysPUWA were mostly associated to proteobacteria, particularly the Burkholderiales family, suggesting a central role of this group in sulfur assimilation and cycling.

\section{Carbon Fixation}

Defining features of arid soils are low productivity and low organic carbon content (Delgado-Baquerizo et al., 2013). Hyperaridity imposes severe constraints on oxygenic photosynthesis, for which water is the electron donor (WarrenRhodes et al., 2006). Furthermore, soil communities outside of sheltered fertile islands (i.e., hypoliths, endoliths, or biological soil crusts) typically have a very low abundance of phototrophic cyanobacteria (Makhalanyane et al., 2013; Stomeo et al., 2013). Perhaps not surprisingly, transcription of photosynthetic pathway genes and phototrophic organisms was limited in our sequence dataset (Figures 1B,A). Notably, reads classified within the Glyoxylate and Dicarboxylate pathway (2.0\%) exceeded those assigned to photosynthetic KEGG pathways and, surprisingly, also significantly exceeded those from the TCA cycle $(0.3 \%$ and $1.6 \%$, respectively, two-tailed $t$-test $p<0.005$ ) (Figure 1B). We also observed a higher number of transcripts assigned to acetyl-CoA synthetase (ACSS, $9874 \mathrm{cpm}$ ) and formate dehydrogenase $(\mathrm{FDH}, 10254 \mathrm{cpm})$ compared to RuBisCO ( $r b c L / S, 2672 \mathrm{cpm}$ ) (Figure 1B). These observations strongly suggest that chemoautotrophic ("dark") carbon fixation and/or $\mathrm{CO}_{2}$ reassimilation mechanisms are important microbial processes by which inorganic $\mathrm{C}$ enters the soil microbial community. Chemoautotrophic carbon fixation has been shown as an important process in marine environments, even when photosynthesis is active (Palovaara et al., 2014; Aylward et al., 2015), and is potentially a major process in soils (King and Weber, 2007; Pratscher et al., 2011). We therefore examined the activity of carboxylase genes, and their distribution between different families of microorganisms, in greater depth.

Although RuBisCO gene transcripts $(r b c)$ from the CalvinBenson-Bassham (CBB) cycle were significant (average $2672 \mathrm{cpm}$ ) (Figure 1B), the majority were assigned to non-photosynthesizing alpha-Proteobacteria rather than to Cyanobacteria (Figure 2C). This suggested that the $\mathrm{CBB}$ cycle acted predominantly in chemoautotrophic $\mathrm{CO}_{2}$ fixation or as an electron sink (Badger and Bek, 2008; McKinlay and Harwood, 2010), rather than in photosynthesis.

Orthologs of the acetyl-CoA synthase ACSS (9874 cpm), CO dehydrogenase coxS $(1701 \mathrm{cpm})$ and formate dehydrogenase FDH $(10254 \mathrm{cpm})$ genes, involved in the reductive acetyl-CoA cycle (Wood-Ljungdahl pathway), were significantly transcribed in a wide range of taxa (Figure 2C). These carboxylases are widely distributed in soil bacteria (King and Weber, 2007) and are active in desert actinobacteria (Sghaier et al., 2016). The activity of these genes in Namib Desert soil microbial communities may be related to the very low energy requirements and the capacity to coassimilate one-carbon compounds or acetate of this pathway (Fuchs, 2011), making it well suited to oligotrophic niches.

The reductive citric acid cycle (Arnon-Buchanan cycle) carboxylases kor (2-oxoglutarate synthase) and icd (isocitrate dehydrogenase) were transcribed by many actinobacterial families, but surprisingly not by Rubrobacteraceae (Figure 2C). Instead, Rubrobacteraceae transcribed the acetyl and propionylCoA carboxylase $p c c B$ and $a c c A / C / D$, the phosphoenolpyruvate (PEP) carboxylase $p c k A$ and the pyruvate synthase por, which participate in other pathways of chemoautotrophic carbon fixation (Fuchs, 2011; Figure 2C). These pathways could only be partialy detected in Rubrobacteraceae, as transcripts for several key genes (e.g., malonyl-CoA reductase, 4-hydroxybutyrylCoA dehydratase) were not identified. These pathways, either full or partial, allow prokaryotes to coassimilate reduced and uncommon C compounds and to fix carbonate (Fuchs, 2011; Zarzycki and Fuchs, 2011). Our results therefore suggest that the actinobacterial Rubrobacteraceae family may be important in 


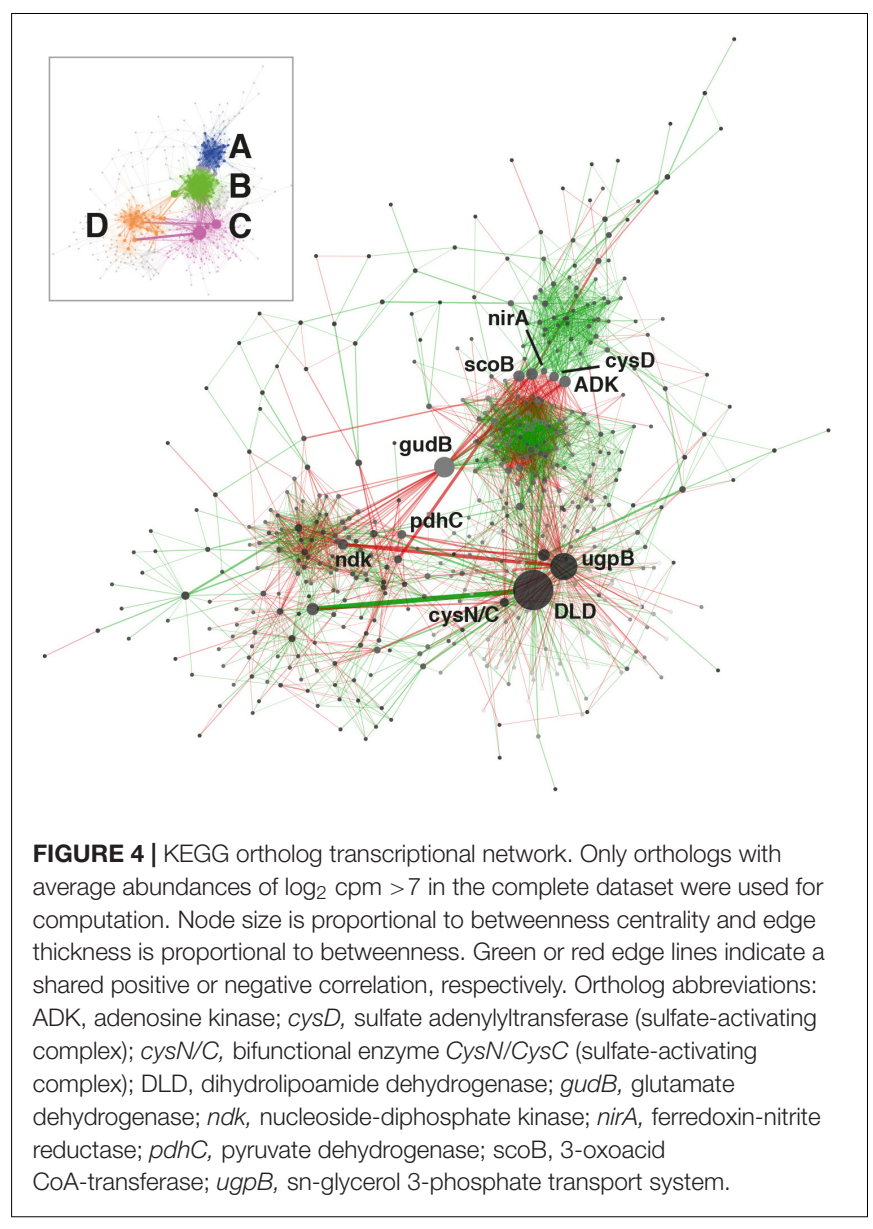

inorganic carbon acquisition in desert soils, partly due to a high plasticity in chemoautotrophic metabolism.

\section{Circadian Differential Gene Expression}

Environmental variations often cause microbial communities to exhibit differential activity profiles over temporal timescales (e.g., daily or seasonally), both in phototrophic and nonphototrophic groups (van der Meer et al., 2005; Klatt et al., 2013; Ottesen et al., 2013, 2014; Aylward et al., 2015). An initial permutation test on sample group dissimilarities was performed using ANOSIM (Oksanen et al., 2017). The analysis showed a low but significant dissimilarity between "day" (12:00 and 18:00) and "night" (24:00 and 6:00) groups $(R=0.2053 ; p=0.018,999$ permutations). These results are consistent with the hypothesis that diurnal and reciprocal variations in soil temperature and humidity (Supplementary Figure S2) are significant drivers of gene transcription in the microbial community.

Diel transcriptional periodicity was also examined at the gene ortholog level using EdgeR (Robinson et al., 2010). Time pairs were contrasted independently, as well as "day" vs. "night" groups as defined above. Interestingly, pairwise comparisons identified no differentially expressed orthologs $(p>0.05)$ between the 12:00 and 18:00 or between the 24:00 and 6:00 datasets. When "day" and "night" data were contrasted, 13 of 2265 orthologs $(0.57 \%)$ were significantly $(p<0.05)$ induced during the night (Supplementary Table S4). None were highly transcribed orthologs, suggesting that under extreme dry conditions, desert soil communities are generally functionally stable and that their principal functions are not strongly regulated on a diel scale.

This conclusion has implications in terms of the perceived drivers of microbial community function, as our results suggest that the constant xeric stress is a more significant driver of in situ functionality than daily environmental variations (temperature, soil atmospheric moisture or light). We predict that this functional stability would only be substantially disrupted by stochastic events such as rainfall, which is recognized as a main driver of community assembly and activity in arid soil environments (Belnap et al., 2005; Pointing and Belnap, 2012; Frossard et al., 2015; Armstrong et al., 2016; Scola et al., 2017).

Surprisingly, we observed a marked enrichment in differentially transcribed eukaryal orthologs, including tubulin, dynein, myosin, SF3B, dnaJ, and ANP1 genes (Supplementary Table S4). This suggests that the active fungi, which only represented $2.8 \%$ of the total transcripts, were most active during the cooler and higher atmospheric humidity night hours. This functional behavior contrasts with the stable activity pattern observed for the rest of the community, but is consistent with previous observations for fungi and lichens from arid environments, where these taxa appear to grow optimally during small air moisture pulses (Palmer et al., 1987; Jacobson et al., 2015).

\section{Transcriptional Network Analysis}

The temporal co-variation of KOs was determined in order to examine whether coordinated patterns of gene transcription existed within the soil community. 624 orthologs were used to construct a transcriptional network, $83.3 \%$ of which (520) clustered into 4 distinct modules (A to D, Figure 4). The larger clusters A and B were composed of positively interrelated orthologs, although no specific functional enrichment within each module was observed.

The principal transcriptional network clusters were connected through three orthologs: the dihydrolipoamide dehydrogenase DLD, the G3P transporter subunit $u g p B$ and the glutamate dehydrogenase gene $g u d B$. These genes occupy network hub positions and changes in their transcriptional status could result in large shifts in community function. The dominant metabolic function associated with the highly transcribed (3917 cpm, Figure 1B) DLD gene is associated with the TCA cycle, but this gene has also been shown to affect sugar transport and capsule formation via direct interactions with membrane transporters (Tyx et al., 2011). The importance of exopolysaccharides in desiccation resistance (Lebre et al., 2017), and the TCA cycle in carbon metabolism regulation, support the centrality of DLD in the community network. The gene $u g p B$, as previously discussed, was linked to the rhizobial community as part of a nearly exclusive phosphorus assimilation mechanism (Figure 2B). The $g u d B$ gene product catalyzes the synthesis of glutamate, the principal acceptor metabolite in $\mathrm{NH}_{3}$ assimilation (Merrick and Edwards, 1995; Figure 3A).

The network was also characterized by a group of orthologs connecting the main clusters $\mathrm{A}$ and $\mathrm{B}$. Three of these are involved 
in nitrogen (nirA) (Merrick and Edwards, 1995; Figure 3A), sulfur (cysD) (Pinto et al., 2004) and central carbon metabolism $(s c o B)$ (Corthésy-Theulaz et al., 1997; Figure 1B).

Globally, network analysis suggested that transcriptional activity of the community was structured around a selection of hub genes involved in the central steps of nitrogen (nirA, $g u d B)$ (Figure 3A) and sulfate assimilation (cysD, cys $N / C$ ), phosphorus acquisition $(u g p B)$ (Figure 3B) and carbohydrate metabolism (DLD, scoB). The network analysis did not significantly implicate genes related to environmental stress resistance and damage repair (e.g., chaperones, proteases, SOD, uvr, rec), despite these genes being consistently transcribed (Figure 1).

\section{CONCLUSION}

It is widely accepted that the extreme conditions in hot desert open soils limit both microbial and plant life (Pointing and Belnap, 2012; Makhalanyane et al., 2015) and that microbial activity is spatially fragmented, temporally limited and water-driven (Belnap et al., 2005; Pointing and Belnap, 2012; Collins et al., 2014). We have demonstrated that a diverse and consistently active edaphic microbial community exists in hyperarid Namib Desert soils, and that the "active" community is dominated by non-photosynthetic bacteria. Transcripts from all central metabolic pathway genes were detected, suggesting consistent transcriptional activity during the study period. We therefore suggest that desiccationresistant microbial subpopulations remain active and able to proliferate during dry periods, rather than surviving in inactive states (Harrison et al., 2007). Despite the observation of regular environmental fluctuations, only moderate diel changes were observed in prokaryotic transcriptional activity, although a significant activation of fungal genes was noted during the night hours.

Our results highlight the importance of nutrient acquisition for the maintenance of a potentially active microbial population in hyperarid desert soils. However, in contrast to expectations for this extreme environment, stress related gene transcripts were not core elements of functional assemblies, despite their known importance for microbial survival.

Overall, our results show that mRNA transcript analyses can provide valuable information on potential community

\section{REFERENCES}

Albuquerque, L., and da Costa, M. S. (2014). "The Family Rubrobacteraceae," in The Prokaryotes, eds E. F. DeLong, S. Lory, E. Stackebrandt, and F. Thompson (Heidelberg: Springer), 861-866. doi: 10.1007/978-3-642-30138-4_202

Armstrong, A., Valverde, A., Ramond, J.-B., Makhalanyane, T. P., Jansson, J. K., Hopkins, D. W., et al. (2016). Temporal dynamics of hot desert microbial communities reveal structural and functional responses to water input. Sci. Rep. 6:34434. doi: 10.1038/srep34434

Aylward, F. O., Eppley, J. M., Smith, J. M., Chavez, F. P., Scholin, C. A., and DeLong, E. F. (2015). Microbial community transcriptional networks are conserved in three domains at ocean basin scales. Proc. Natl. Acad. Sci. U.S.A. 112, 5443-5448. doi: 10.1073/pnas.1502883112 functionality in dry soil habitats and suggest that these communities may be important in local biogeochemical cycling. This approach is not only more detailed but also potentially offers a better estimation of microbial activity states than rRNA amplicon sequencing (Blazewicz et al., 2013). Future research should be directed toward understanding the kinetics of microbial processes, and particularly carbon fixation, during dry periods in desert soil ecosystems.

\section{AUTHOR'S NOTE}

This work has been made available as a preprint ahead of publication in the bioRxiv repository (León-Sobrino et al., 2018) and was assigned the doi: 10.1101/432427 (see References).

\section{AUTHOR CONTRIBUTIONS}

CL-S, J-BR, and DC conceived the experiment and participated in the interpretation of results and writing of the manuscript. GM-K provided logistical support and field advice in the Namib Desert. CL-S performed all experimental work and bioinformatic analysis of the sequencing output. DC provided the funding.

\section{FUNDING}

The authors acknowledge funding support from the University of Pretoria and the South African National Research Foundation (Grant No. 95565).

\section{ACKNOWLEDGMENTS}

The authors wish to thank the Gobabeb Research and Training Centre personnel for their assistance, advice and for providing access to their facilities during the sampling process.

\section{SUPPLEMENTARY MATERIAL}

The Supplementary Material for this article can be found online at: https://www.frontiersin.org/articles/10.3389/fmicb. 2019.01054/full\#supplementary-material

Badger, M. R., and Bek, E. J. (2008). Multiple Rubisco forms in proteobacteria: their functional significance in relation to $\mathrm{CO} 2$ acquisition by the $\mathrm{CBB}$ cycle. J. Exp. Bot. 59, 1525-1541. doi: 10.1093/jxb/erm297

Báez, S., Fargione, J., Moore, D. I., Collins, S. L., and Gosz, J. R. (2007). Atmospheric nitrogen deposition in the northern Chihuahuan desert: temporal trends and potential consequences. J. Arid Environ. 68, 640-651. doi: 10.1016/ J.JARIDENV.2006.06.011

Belasco, J. G., and Brawerman, G. (1993). Control of Messenger RNA Stability. Cambridge, MA: Academic Press.

Belnap, J., Welter, J. R., Grimm, N. B., Barger, N., and Ludwig, J. A. (2005). Linkages between microbial and hydrologic processes in arid and semiarid watersheds. Ecology 86, 298-307. doi: 10.1890/030567 
Blazewicz, S. J., Barnard, R. L., Daly, R. A., and Firestone, M. K. (2013). Evaluating rRNA as an indicator of microbial activity in environmental communities: limitations and uses. ISME J. 7, 2061-2068. doi: 10.1038/ismej.2013.102

Brzoska, P., and Boos, W. (1988). Characteristics of a ugp-encoded and phoBdependent glycerophosphoryl diester phosphodiesterase which is physically dependent on the ugp transport system of Escherichia coli. J. Bacteriol. 170, 4125-4135. doi: 10.1128/jb.170.9.4125-4135.1988

Brzoska, P., Rimmele, M., Brzostek, K., and Boos, W. (1994). The pho regulondependent Ugp uptake system for glycerol-3-phosphate in Escherichia coli is trans inhibited by Pi. J. Bacteriol. 176, 15-20. doi: 10.1128/jb.176.1.15-20.1994

Cleveland, C. C., and Liptzin, D. (2007). C:N:P stoichiometry in soil: is there a "Redfield ratio" for the microbial biomass? Biogeochemistry 85, 235-252. doi: 10.1007/s10533-007-9132-0

Collins, S. L., Belnap, J., Grimm, N. B., Rudgers, J. A., Dahm, C. N., D’Odorico, P., et al. (2014). A multiscale, hierarchical model of pulse dynamics in aridland ecosystems. Annu. Rev. Ecol. Evol. Syst. 45, 397-419. doi: 10.1146/annurevecolsys-120213-091650

Corthésy-Theulaz, I. E., Bergonzelli, G. E., Henry, H., Bachmann, D., Schorderet, D. F., Blum, A. L., et al. (1997). Cloning and characterization of Helicobacter pylori succinyl CoA:acetoacetate CoA-transferase, a novel prokaryotic member of the CoA-transferase family. J. Biol. Chem. 272, 25659-25667. doi: 10.1074/ JBC.272.41.25659

Delgado-Baquerizo, M., Maestre, F. T., Gallardo, A., Bowker, M. A., Wallenstein, M. D., Quero, J. L., et al. (2013). Decoupling of soil nutrient cycles as a function of aridity in global drylands. Nature 502, 672-676. doi: 10.1038/nature12670

Deng, Y., Jiang, Y.-H., Yang, Y., He, Z., Luo, F., and Zhou, J. (2012). Molecular ecological network analyses. BMC Bioinformatics 13:113. doi: 10.1186/14712105-13-113

Ding, H., Yip, C. B., Geddes, B. A., Oresnik, I. J., and Hynes, M. F. (2012). Glycerol utilization by Rhizobium leguminosarum requires an $\mathrm{ABC}$ transporter and affects competition for nodulation. Microbiology 158, 1369-1378. doi: 10.1099/mic.0.057281-0

Eckardt, F. D., Soderberg, K., Coop, L. J., Muller, A. A., Vickery, K. J., Grandin, R. D., et al. (2013). The nature of moisture at Gobabeb, in the central Namib Desert. J. Arid Environ. 93, 7-19. doi: 10.1016/j.jaridenv.2012.01.011

Favet, J., Lapanje, A., Giongo, A., Kennedy, S., Aung, Y.-Y., Cattaneo, A., et al. (2013). Microbial hitchhikers on intercontinental dust: catching a lift in Chad. ISME J. 7, 850-867. doi: 10.1038/ismej.2012.152

Frossard, A., Ramond, J.-B., Seely, M., and Cowan, D. A. (2015). Water regime history drives responses of soil Namib Desert microbial communities to wetting events. Sci. Rep. 5:12263. doi: 10.1038/srep12263

Fuchs, G. (2011). Alternative pathways of carbon dioxide fixation: insights into the early evolution of life? Annu. Rev. Microbiol. 65, 631-658. doi: 10.1146/ annurev-micro-090110-102801

Gunnigle, E., Frossard, A., Ramond, J.-B., Guerrero, L., Seely, M., and Cowan, D. A. (2017). Diel-scale temporal dynamics recorded for bacterial groups in Namib Desert soil. Sci. Rep. 7:40189. doi: 10.1038/srep40189

Hansen, M. C., Tolker-Nielsen, T., Givskov, M., and Molin, S. (1998). Biased 16S rDNA PCR amplification caused by interference from DNA flanking the template region. FEMS Microbiol. Ecol. 26, 141-149. doi: 10.1111/j.1574-6941. 1998.tb00500.x

Harrison, J. J., Ceri, H., and Turner, R. J. (2007). Multimetal resistance and tolerance in microbial biofilms. Nat. Rev. Microbiol. 5, 928-938. doi: 10.1038/ nrmicro1774

Jacobson, K., Van Diepeningen, A., Evans, S., Fritts, R., Gemmel, P., Marsho, C., et al. (2015). Non-rainfall moisture activates fungal decomposition of surface litter in the Namib Sand Sea. PLoS One 10:e0126977. doi: 10.1371/journal.pone. 0126977

Jia, Y., Yu, G., Gao, Y., He, N., Wang, Q., Jiao, C., et al. (2016). Global inorganic nitrogen dry deposition inferred from ground- and space-based measurements. Sci. Rep. 6:19810. doi: 10.1038/srep19810

Johnson, R. M., Ramond, J.-B., Gunnigle, E., Seely, M., and Cowan, D. A. (2017). Namib desert edaphic bacterial, fungal and archaeal communities assemble through deterministic processes but are influenced by different abiotic parameters. Extremophiles 21, 381-392. doi: 10.1007/s00792-016-0911-1

Kanehisa, M., Sato, Y., Kawashima, M., Furumichi, M., and Tanabe, M. (2016). KEGG as a reference resource for gene and protein annotation. Nucleic Acids Res. 44, D457-D462. doi: 10.1093/nar/gkv1070
King, G. M., and Weber, C. F. (2007). Distribution, diversity and ecology of aerobic CO-oxidizing bacteria. Nat. Rev. Microbiol. 5, 107-118. doi: 10.1038/ nrmicro1595

Klatt, C. G., Liu, Z., Ludwig, M., Kühl, M., Jensen, S. I., Bryant, D. A., et al. (2013). Temporal metatranscriptomic patterning in phototrophic Chloroflexi inhabiting a microbial mat in a geothermal spring. ISME J. 7, 1775-1789. doi: 10.1038 /ismej.2013.52

Laity, J. (2008). Deserts and Desert Environments. Chichester: Wiley-Blackwell.

Langmead, B., and Salzberg, S. L. (2012). Fast gapped-read alignment with Bowtie 2. Nat. Methods 9, 357-359. doi: 10.1038/nmeth.1923

Lebre, P. H., De Maayer, P., and Cowan, D. A. (2017). Xerotolerant bacteria: surviving through a dry spell. Nat. Rev. Microbiol. 15, 285-296. doi: 10.1038/ nrmicro.2017.16

León-Sobrino, C., Ramond, J.-B., Maggs-Kölling, G., and Cowan, D. A. (2018). Nutrient acquisition, rather than stress response over diel cycles, drives microbial transcription in a dessicated namib desert soil. bioRxiv [Preprint]. doi: 10.1101/432427

Lidbury, I. D. E. A., Murphy, A. R. J., Fraser, T. D., Bending, G. D., Jones, A. M. E., Moore, J. D., et al. (2017). Identification of extracellular glycerophosphodiesterases in Pseudomonas and their role in soil organic phosphorus remineralisation. Sci. Rep. 7:2179. doi: 10.1038/s41598-017-02 327-6

Lun, A. T. L., Chen, Y., and Smyth, G. K. (2016). It's DE-licious: a recipe for differential expression analyses of RNA-seq experiments using quasi-likelihood methods in edgeR. Methods Mol. Biol. 1418, 391-416. doi: 10.1007/978-1-49393578-9_19

Makhalanyane, T. P., Valverde, A., Gunnigle, E., Frossard, A., Ramond, J.-B., and Cowan, D. A. (2015). Microbial ecology of hot desert edaphic systems. FEMS Microbiol. Rev. 39, 203-221. doi: 10.1093/femsre/fuu011

Makhalanyane, T. P., Valverde, A., Lacap, D. C., Pointing, S. B., Tuffin, M. I., and Cowan, D. A. (2013). Evidence of species recruitment and development of hot desert hypolithic communities. Environ. Microbiol. Rep. 5, 219-224. doi: 10.1111/1758-2229.12003

McCarthy, D. J., Chen, Y., and Smyth, G. K. (2012). Differential expression analysis of multifactor RNA-Seq experiments with respect to biological variation. Nucleic Acids Res. 40, 4288-4297. doi: 10.1093/nar/gks042

McKinlay, J. B., and Harwood, C. S. (2010). Carbon dioxide fixation as a central redox cofactor recycling mechanism in bacteria. Proc. Natl. Acad. Sci. U.S.A. 107, 11669-11675. doi: 10.1073/pnas.1006175107

Merrick, M. J., and Edwards, R. A. (1995). Nitrogen control in bacteria. Microbiol. Rev. 59, 604-622.

Meyer, F., Paarmann, D., D’Souza, M., Olson, R., Glass, E., Kubal, M., et al. (2008). The metagenomics RAST server - a public resource for the automatic phylogenetic and functional analysis of metagenomes. BMC Bioinformatics 9:386. doi: 10.1186/1471-2105-9-386

Nielsen, K. M., Calamai, L., and Pietramellara, G. (2006). "Stabilization of Extracellular DNA and Proteins by Transient Binding to Various Soil Components," in Nucleic Acids and Proteins in Soil, eds P. Nannipieri and K. Smalla (Heidelberg: Springer), 141-157. doi: 10.1007/3-540-29 449-X_7

Normand, P., Benson, D. R., Normand, P., and Benson, D. R. (2015). "Geodermatophilus," in Bergey's Manual of Systematics of Archaea and Bacteria, eds W. B. Whitman, F. Rainey, P. Kämpfer, M. Trujillo, J. Chun, P. DeVos, et al. (Chichester: John Wiley \& Sons, Ltd), 1-4. doi: 10.1002/9781118960608. gbm00044

Oksanen, F. J., Blanchet, G., Friendly, M., Kindt, R., Legendre, P., McGlinn, D., et al. (2017). vegan: Community Ecology Package. R package version 2.4-5. Available at: https://CRAN.R-project.org/package=vegan

Ottesen, E. A., Young, C. R., Eppley, J. M., Ryan, J. P., Chavez, F. P., Scholin, C. A., et al. (2013). Pattern and synchrony of gene expression among sympatric marine microbial populations. Proc. Natl. Acad. Sci. U.S.A. 110, E488-E497. doi: 10.1073/pnas.1222099110

Ottesen, E. A., Young, C. R., Gifford, S. M., Eppley, J. M., Marin, R., Schuster, S. C., et al. (2014). Multispecies diel transcriptional oscillations in open ocean heterotrophic bacterial assemblages. Science 345, 207-212. doi: 10.1126/science. 1252476

Palmer, F. E., Emery, D. R., Stemmler, J., and Staley, J. T. (1987). Survival and growth of microcolonial rock fungi as affected by temperature and 
humidity. New Phytol. 107, 155-162. doi: 10.1111/j.1469-8137.1987.tb0 4889.x

Palovaara, J., Akram, N., Baltar, F., Bunse, C., Forsberg, J., Pedrós-Alió, C., et al. (2014). Stimulation of growth by proteorhodopsin phototrophy involves regulation of central metabolic pathways in marine planktonic bacteria. Proc. Natl. Acad. Sci. U.S.A. 111, E3650-E3658. doi: 10.1073/pnas.1402617111

Pinto, R., Tang, Q. X., Britton, W. J., Leyh, T. S., and Triccas, J. A. (2004). The Mycobacterium tuberculosis cysD and cysNC genes form a stress-induced operon that encodes a tri-functional sulfate-activating complex. Microbiology 150, 1681-1686. doi: 10.1099/mic.0.26894-0

Pointing, S. B., and Belnap, J. (2012). Microbial colonization and controls in dryland systems. Nat. Rev. Microbiol. 10, 551-562. doi: 10.1038/nrmicro2831

Pratscher, J., Dumont, M. G., and Conrad, R. (2011). Ammonia oxidation coupled to $\mathrm{CO} 2$ fixation by archaea and bacteria in an agricultural soil. Proc. Natl. Acad. Sci. U.S.A. 108, 4170-4175. doi: 10.1073/pnas. 1010981108

R Core Team (2017). R: A Language and Environment for Statistical Computing. Vienna: R Foundation for Statistical Computing.

Rainey, F. A., Ray, K., Ferreira, M., Gatz, B. Z., Nobre, M. F., Bagaley, D., et al. (2005). Extensive diversity of ionizing-radiation-resistant bacteria recovered from Sonoran Desert soil and description of nine new species of the genus Deinococcus obtained from a single soil sample. Appl. Environ. Microbiol. 71, 5225-5235. doi: 10.1128/AEM.71.9.5225-5235.2005

Rajeev, L., da Rocha, U. N., Klitgord, N., Luning, E. G., Fortney, J., Axen, S. D., et al. (2013). Dynamic cyanobacterial response to hydration and dehydration in a desert biological soil crust. ISME J. 7, 2178-2191. doi: 10.1038/ismej.2013.83

Ramond, J.-B., Woodborne, S., Hall, G., Seely, M., and Cowan, D. A. (2018). Namib Desert primary productivity is driven by cryptic microbial community N-fixation. Sci. Rep. 8:6921. doi: 10.1038/s41598-018-25078-4

Rashid, A. M., Batey, S. F. D., Syson, K., Koliwer-Brandl, H., Miah, F., Barclay, J. E., et al. (2016). Assembly of $\alpha$-Glucan by GlgE and GlgB in mycobacteria and streptomycetes. Biochemistry 55, 3270-3284. doi: 10.1021/acs.biochem. $6 \mathrm{~b} 00209$

Reich, P., Numbem, S., Almaraz, R., and Eswaran, H. (2001). "Land resource stresses and desertification in Africa," in Responses to Land Degradation. Proc. 2nd. International Conference on Land Degradation and Desertification, Khon Kaen, Thailand, eds E. M. Bridges, D. Hannam, L. R. Oldeman, F. W. T. Pening de Vries, S. J. Scherr, and S. Sompatpanit (New Delhi: Oxford Press).

Reysenbach, A., and Pace, N. R. (1995). "Archaea: a laboratory manual," in Archaea: a Laboratory Manual, eds F. Robb and A. Place (New York, NY: Cold Spring Harbor press), 101-107.

Robinson, M. D., McCarthy, D. J., and Smyth, G. K. (2010). edgeR: a bioconductor package for differential expression analysis of digital gene expression data. Bioinformatics 26, 139-140. doi: 10.1093/bioinformatics/btp616

Robinson, M. D., and Oshlack, A. (2010). A scaling normalization method for differential expression analysis of RNA-seq data. Genome Biol. 11:R25. doi: 10.1186/gb-2010-11-3-r25

Ronca, S., Ramond, J.-B., Jones, B. E., Seely, M., and Cowan, D. A. (2015). Namib desert dune/interdune transects exhibit habitat-specific edaphic bacterial communities. Front. Microbiol. 6:845. doi: 10.3389/fmicb.2015.00845

Scherer, S., Ernst, A., Chen, T.-W., and Böger, P. (1984). Rewetting of droughtresistant blue-green algae: time course of water uptake and reappearance of respiration, photosynthesis, and nitrogen fixation. Oecologia 62, 418-423. doi: 10.1007/BF00384277

Schmieder, R., and Edwards, R. (2011). Quality control and preprocessing of metagenomic datasets. Bioinformatics 27, 863-864. doi: 10.1093/ bioinformatics/btr026

Scholz, H. (1972). The soils of the central Namib desert with special consideration of the soils in the vicinity of Gobabeb. Madoqua 1972, 33-51.

Schowanek, D., and Verstraete, W. (1990). Phosphonate utilization by bacteria in the presence of alternative phosphorus sources. Biodegradation 1, 43-53. doi: $10.1007 / B F 00117050$

Schulze-Makuch, D., Wagner, D., Kounaves, S. P., Mangelsdorf, K., Devine, K. G., de Vera, J.-P., et al. (2018). Transitory microbial habitat in the hyperarid Atacama Desert. Proc. Natl. Acad. Sci. U.S.A. 115, 2670-2675. doi: 10.1073/pnas. 1714341115

Scola, V., Ramond, J.-B., Frossard, A., Zablocki, O., Adriaenssens, E. M., Johnson, R. M., et al. (2017). Namib desert soil microbial community diversity, assembly, and function along a natural xeric gradient. Microb. Ecol. 75, 193-203. doi: 10.1007/s00248-017-1009-8

Seely, M., and Pallet, J. (2008). Namib: Secrets of a Desert Uncovered. Windhoek: Venture Publications.

Segev, E., Smith, Y., and Ben-Yehuda, S. (2012). RNA dynamics in aging bacterial spores. Cell 148, 139-149. doi: 10.1016/J.CELL.2011.11.059

Sellstedt, A., and Richau, K. H. (2013). Aspects of nitrogen-fixing actinobacteria, in particular free-living and symbiotic Frankia. FEMS Microbiol. Lett. 342, 179-186. doi: 10.1111/1574-6968.12116

Sghaier, H., Hezbri, K., Ghodhbane-Gtari, F., Pujic, P., Sen, A., Daffonchio, D., et al. (2016). Stone-dwelling actinobacteria Blastococcus saxobsidens, modestobacter marinus and Geodermatophilus obscurus proteogenomes. ISME J. 10, 21-29. doi: 10.1038/ismej.2015.108

Shannon, P., Markiel, A., Ozier, O., Baliga, N. S., Wang, J. T., Ramage, D., et al. (2003). Cytoscape: a software environment for integrated models of biomolecular interaction networks. Genome Res. 13, 2498-2504. doi: 10.1101/ gr.1239303

Stomeo, F., Valverde, A., Pointing, S. B., McKay, C. P., Warren-Rhodes, K. A., Tuffin, M. I., et al. (2013). Hypolithic and soil microbial community assembly along an aridity gradient in the Namib Desert. Extremophiles 17, 329-337. doi: 10.1007/s00792-013-0519-7

Štovíček, A., Kim, M., Or, D., and Gillor, O. (2017). Microbial community response to hydration-desiccation cycles in desert soil. Sci. Rep. 7:45735. doi: 10.1038/ srep45735

Szymanski, M., Zielezinski, A., Barciszewski, J., Erdmann, V. A., and Karlowski, W. M. (2016). 5SRNAdb: an information resource for 5S ribosomal RNAs. Nucleic Acids Res. 44, D180-D183. doi: 10.1093/nar/gkv1081

Tyx, R. E., Roche-Hakansson, H., and Hakansson, A. P. (2011). Role of dihydrolipoamide dehydrogenase in regulation of raffinose transport in Streptococcus pneumoniae. J. Bacteriol. 193, 3512-3524. doi: 10.1128/JB.014 $10-10$

van der Meer, M. T. J., Schouten, S., Bateson, M. M., Nübel, U., Wieland, A., Kühl, M., et al. (2005). Diel variations in carbon metabolism by green nonsulfur-like bacteria in alkaline siliceous hot spring microbial mats from Yellowstone National Park. Appl. Environ. Microbiol. 71, 3978-3986. doi: 10.1128/AEM.71.7.3978-3986. 2005

Vikram, S., Guerrero, L. D., Makhalanyane, T. P., Le, P. T., Seely, M., and Cowan, D. A. (2016). Metagenomic analysis provides insights into functional capacity in a hyperarid desert soil niche community. Environ. Microbiol. 18, 1875-1888. doi: $10.1111 / 1462-2920.13088$

Warren-Rhodes, K. A., Rhodes, K. L., Pointing, S. B., Ewing, S. A., Lacap, D. C., Gómez-Silva, B., et al. (2006). Hypolithic cyanobacteria, dry limit of photosynthesis, and microbial ecology in the hyperarid atacama desert. Microb. Ecol. 52, 389-398. doi: 10.1007/s00248-006-9055-7

White, A. K., and Metcalf, W. W. (2007). Microbial metabolism of reduced phosphorus compounds. Annu. Rev. Microbiol. 61, 379-400. doi: 10.1146/ annurev.micro.61.080706.093357

Zablocki, O., Adriaenssens, E. M., and Cowan, D. (2015). Diversity and ecology of viruses in hyperarid desert soils. Appl. Environ. Microbiol. 82, 770-777. doi: 10.1128/AEM.02651-15

Zarzycki, J., and Fuchs, G. (2011). Coassimilation of organic substrates via the autotrophic 3-hydroxypropionate bi-cycle in Chloroflexus aurantiacus. Appl. Environ. Microbiol. 77, 6181-6188. doi: 10.1128/AEM.007 05-11

Conflict of Interest Statement: The authors declare that the research was conducted in the absence of any commercial or financial relationships that could be construed as a potential conflict of interest.

Copyright (c) 2019 León-Sobrino, Ramond, Maggs-Kölling and Cowan. This is an open-access article distributed under the terms of the Creative Commons Attribution License (CC BY). The use, distribution or reproduction in other forums is permitted, provided the original author(s) and the copyright owner(s) are credited and that the original publication in this journal is cited, in accordance with accepted academic practice. No use, distribution or reproduction is permitted which does not comply with these terms. 